\title{
Sleep characteristics, sleep problems, and associations of self-efficacy among German university students
}

\author{
Angelika A Schlarb ${ }^{1,2}$ \\ Dominika Kulessa ${ }^{1, *}$ \\ Marco D Gulewitsch ${ }^{1, *}$ \\ 'Faculty of Science, Department \\ of Psychology, University of \\ Tübingen, ${ }^{2}$ Faculty of Psychology, \\ University of Koblenz-Landau, \\ Germany \\ *These authors contributed equally to \\ this work
}

This article was published in the following Dove Press journal:

Nature and Science of Sleep

8 February 2012

Number of times this article has been viewed
Background: Sleep problems, especially insomnia, are a common complaint among adults. International studies on university students have shown prevalence rates between $4.7 \%$ and $36.2 \%$ for sleep difficulties, and $13.1 \%$ and $28.1 \%$ for insomnia. Sleep problems are associated with lower social and academic performance and can have a severe impact on psychological and physical health.

Objective: The goal of this study was to outline sleep characteristics, prevalence of sleep problems, insomnia, and associations with self-efficacy among German university students.

Methods: A total of 2196 university students (70.9\% women; mean age 24.16 years) participated in the study. Sleep characteristics, sleep problems, insomnia, and self-efficacy were assessed using a questionnaire.

Results and conclusion: Analyses revealed that more than $16 \%$ of surveyed students needed more than 30 minutes to fall asleep. About $7.7 \%$ of the students suffered from insomnia. Short sleep was significantly associated with a considerably increased rate of insomnia (20\%). Insomniacs showed lower self-efficacy than students without sleep problems.

Keywords: university students, sleep characteristics, sleep problems, insomnia, self-efficacy

\section{Introduction}

Recently, sleep research has focused not only on children and adults but also on students in particular. ${ }^{1-4}$ These studies have shown that sleep problems such as difficulty falling asleep and maintaining sleep are common complaints among university students. ${ }^{2-8}$ Indeed, $4.7 \%$ of 1200 students in Switzerland reported poor sleep quality. ${ }^{9}$ Moreover, Buboltz and colleagues ${ }^{10}$ showed that $15 \%$ of US college students reported poor sleep quality and $73 \%$ indicated at least occasional sleep problems. Ban and Lee $^{11}$ determined that $36.2 \%$ of university students in Korea had sleep disturbances. Pronounced insomnia is also common among students; Nadorff et $\mathrm{al}^{2}$ reported a prevalence of $13.1 \%$ for insomnia symptoms among US college students in West Virginia. In addition, according to the research of Loayza et al, ${ }^{12} 28.1 \%$ of medical students in Brazil suffered from insomnia.

Students are faced with challenging facets of their lives such as exams, work, family, relationships, and classes. Sleep is normally not the focus of health-related behavior at this age, but nevertheless the amount of requirements often leads to stress. ${ }^{13,14}$ As is well-known, daily hassles and chronic stress are factors for the onset and maintenance of sleep problems. ${ }^{15}$ Thus, about $30 \%$ of students are often sleep deprived with less sleep than recommended and have an overall mean of sleep duration of 7.02 hours per night. ${ }^{13}$ Sleep problems can lead to further stress: $54.1 \%$ of the students asked by submit your manuscript | www.dovepress.com

Dovepress

http://dx.doi.org//0.2147/NSS.S2797।
Nature and Science of Sleep 2012:4 I-7

(C) 2012 Schlarb et al, publisher and licensee Dove Medical Press Ltd. This is an Open Access article which permits unrestricted noncommercial use, provided the original work is properly cited. 
Schleider and Güntert ${ }^{16}$ reported sleep deprivation/sleepiness as a cause for their learning and working problems.

As sleep problems are associated with numerous complaints in social ${ }^{16}$ and academic performance, such as difficulties in concentration ${ }^{17}$ as well as psychological and physical health, ${ }^{18}$ coherence and causal relationships should be discussed. Coping strategies and problem-solving competence are factors disputed for differences in health and sleep quality. ${ }^{18-21}$

Klomegah $^{22}$ showed that a predictor of academic success is high school graduation and self-efficacy. Self-efficacy is denoted as the ability to manage future behavior and the expectation that a person has toward actions mastered by self-competence. According to Bandura, ${ }^{23}$ self-referred cognitions influence thinking, feeling, motivation, and behavior in a significant way. He suggests that students' beliefs in their self-efficacy, to regulate their own competence, play a key role in mastering academic demands. ${ }^{24}$ In-line with this, Bouchard and colleagues discussed low self-efficacy in the context of sleep problems. ${ }^{25}$

To our knowledge, there has been no investigation of sleep problems and self-efficacy among university students in Germany to date. The goal of this study is to close this gap by outlining sleep characteristics, prevalence of insomnia, and to highlight the associations with self-efficacy among German university students. Specifically, we wanted to observe the hours of sleep per night, the time of going to bed, the time students woke up in the morning, and the time they needed to fall asleep during the last month. Additionally, we wanted to explore the occurrence of night waking and how fitful their sleep was. Furthermore, to avoid answers on the basis of an acute state, we based all of these questions on the last month. Alongside these sleep characteristics, our goal was to evaluate the prevalence of insomnia in a student population.

\section{Methods}

\section{Questionnaire}

The questionnaire used in the present study was embedded in an Internet-based survey on gastrointestinal complaints and stress in university students. Only the results concerning sleep questions are reported in this paper.

The online questionnaire consisted of four sections: (1) sociodemographic information (age, gender, number of semesters, place of study), (2) questions on gastrointestinal symptoms and other somatic complaints, (3) assessment of sleep characteristics, and (4) assessment of subjective selfefficacy using the well-validated general self-efficacy scale
(GSE) by Schwarzer and Jerusalem. ${ }^{26}$ Time suggested for completion of the questionnaire was about 20 minutes.

The assessment of sleep characteristics was based on questions about time of going to bed, awaking in the morning, and about time needed to fall asleep, during the previous month. Additionally, the occurrence of awaking during the night and fitful sleep per week in the last month were ascertained. If sleep problems were reported, questions were asked about resulting impairment of work habits and concentration.

Insomnia was defined (according to the International Classification of Sleep Disorders - Second Edition ${ }^{27}$ and Lichtstein et al $)^{28}$ as:

- falling asleep time lasting longer than 30 minutes at least three times per week

- awaking during the night that was regarded as disturbing at least three nights per week

- at least a moderate impairment of work habits and concentration caused by less restful sleep.

\section{Recruitment of participants}

Brief information about the study and a hyperlink to the online questionnaire were sent via email to all students of Tuebingen University (23,222 students in 2009). To avoid stress due to exams, the study was introduced at the beginning of the semester. To increase the sample size, local students were encouraged to pass on the survey hyperlink to students from other universities.

The study was approved by the ethics committee of the University Hospital, Tuebingen. Online information about the goals of the study and confirmation of anonymity of the data were provided. Informed consent was given by deliberately clicking a relevant statement on the webpage.

\section{Statistics}

Data were analyzed using Statistics 18.0 (SPSS, Chicago, IL). Frequencies were reported as percentages; comparisons between frequency-based data were performed using $\chi^{2}$-tests. Continuous variables were compared using two-tailed independent-sample $t$-tests. For all comparisons, the statistical level of significance was set at $P<0.05$. If not noted explicitly, analyses were executed adjusting for gender using weighting factors, because of the unequal gender ratio in the sample. Furthermore, separate analyses were calculated to allow gender-specific statements. One univariate and two multivariate logistic regression models were performed to calculate odds ratios (ORs) and adjusted ORs, for associations of insomnia with demographic information and factors 
of sleep behavior. All logistic regression results are reported as ORs with associated $95 \%$ confidence intervals.

\section{Results \\ Participants}

A total of 1795 students from the University of Tuebingen entered the study. In addition, 604 students from other universities filled out the questionnaire, leading to a total sample of 2399 students (1701 females, 696 males, two unknown). The mean (M) age of participants was 24.16 years (standard deviation [SD] $=3.89$ ) with an age range of $17-65$ years. Only $5.4 \%$ of the sample was aged $>30$ years and $0.8 \%>40$ years. The average duration of studies in the complete sample (counted in semesters; 2 semesters $=1$ year) was $\mathrm{M}=6.18$ semesters $(\mathrm{SD}=3.58)$ with the range $1-27$ semesters.

Of all 2399 students, 2196 completed the questionnaire fully $(91.6 \%)$. Noncompleting participants did not differ significantly from completers regarding age, gender, or number of semesters.

\section{Sleep characteristics of students}

Surveyed students reported a gender-adjusted overall sleep duration of $\mathrm{M}=456.00$ minutes (7.6 hours) per night ( $\mathrm{SD}=70.84)$ with only minor gender differences: $\mathrm{M}=450.31$ minutes $(\mathrm{SD}=68.62)$ in males and $\mathrm{M}=461.66$ minutes $(\mathrm{SD}=72.57)$ in females.

The time going to bed was surveyed using horal categories. The majority of students $(72.4 \%)$ went to bed between $10 \mathrm{pm}$ and $12 \mathrm{am}$ (inclusive). Details are presented in Table 1 . Added together, $26.5 \%$ of students went to sleep at or after $1 \mathrm{am}$, accompanied by a distinct difference between the genders $(34.2 \%$ of male students vs $18.5 \%$ of female students; $\left.\chi^{2}=66.086 ; P=0.000\right)$. Students who went to bed at 1 am or later, showed a significantly elevated prevalence of insomnia $\left(9.6 \%\right.$ vs $\left.7.0 \% ; \chi^{2}=3.998 ; P=0.046\right)$.

Table I Time going to bed among university students

\begin{tabular}{lll}
\hline Go to bed at & Frequency & Percentage \\
\hline $8 \mathrm{pm}$ & 3 & 0.2 \\
$9 \mathrm{pm}$ & 17 & 0.8 \\
$10 \mathrm{pm}$ & 187 & 8.5 \\
$1 \mathrm{pm}$ & 682 & 31.1 \\
$12 \mathrm{am}$ & 721 & 32.8 \\
$1 \mathrm{am}$ & 374 & 17.0 \\
$2 \mathrm{am}$ & 157 & 7.1 \\
$3 \mathrm{am}$ & 40 & 1.8 \\
$4 \mathrm{am}$ & 7 & 0.3 \\
$5 \mathrm{am}$ & 6 & 0.3 \\
\hline
\end{tabular}

Since time needed to fall asleep was noted using given categories, no mean can be calculated; the majority of respondents $(84.1 \%)$ fell asleep within 30 minutes, whereas $16 \%$ needed more than 30 minutes to fall asleep, and falling asleep took longer than 1 hour for $5.7 \%$ of the students. Table 2 lists detailed information and gender differences. There was a significant shift between the 15 minute and the 30 minute category, indicating a longer period of falling asleep in women.

\section{Prevalence of sleep disturbances and insomnia in students}

Difficulties falling asleep (=lasting longer than 30 minutes at least three times per week) are quite prevalent in this sample: adjusting for gender, 327 students (14.9\%) reported this issue. There was only a slight difference between genders: $14.1 \%$ in males and $15.7 \%$ in females $\left(\chi^{2}=0.906 ; P=0.341\right)$. Approximately one quarter of the sample (25.9\%) indicate frequent awakenings at night (=at least three nights per week) and regarded this as disturbing. Females were slightly more concerned about waking at night $(27.6 \%$ vs $24.2 \%$; $\left.\chi^{2}=2.593 ; P=0.107\right)$. A third of students $(33.3 \%)$ noted fitful sleep at least three nights per week, whereas female students $(36.5 \%)$ were significantly more affected than male students (30.0\%), $\chi^{2}=8.643 ; P=0.003$. Insomnia could be ascertained in $7.7 \%$ of students (adjusted for gender), whereby female students were more likely to fulfill established insomnia criteria $\left(9.3 \%\right.$ vs $\left.6.2 \% ; \chi^{2}=5.573 ; P=0.018\right)$.

Those new to study did not differ from the rest of the sample regarding insomnia $\left(8.0 \%\right.$ vs $7.7 \% ; \chi^{2}=0.037$; $P=0.848)$, but long-term students ( $>12$ semesters) did differ perceptibly. The prevalence of insomnia in long-term students was $13.0 \%$ compared with $7.5 \%$ of the rest $\left(\chi^{2}=4.050\right.$; $P=0.044)$. In medical students $(\mathrm{n}=170)$ the prevalence of insomnia was only $4.1 \%$, but did not differ significantly $\left(\chi^{2}=2.827 ; P=0.093\right)$ from the other participants.

Based on overall sleep duration, surveyed students were classified as short ( $<1 \mathrm{SD}$ from mean), normal, or long sleepers ( $>1$ SD from mean). Sleeping "short" was significantly associated with an increased rate of insomnia. Nearly $20 \%$ of short sleepers fulfilled the criteria for insomnia, whereas only $6.3 \%$ of normal sleepers and $5.1 \%$ of long sleepers did. As reported in Table 3, this effect can be shown for both genders.

The majority of students (58.8\%) got up between 7 am and $8 \mathrm{am}$. The time to get up was classified as "early" (5 am to $7 \mathrm{am}$ ), "normal" (8 am to $9 \mathrm{am}$ ), and "late" (10 am and later). Late risers featured a remarkably elevated 
Table 2 Time needed to fall asleep in the gender adjusted overall sample and split in genders

\begin{tabular}{|c|c|c|c|c|c|c|c|}
\hline \multirow{2}{*}{$\begin{array}{l}\text { Time needed } \\
\text { to fall asleep }\end{array}$} & \multicolumn{2}{|c|}{ Overall sample } & \multicolumn{2}{|c|}{ Female students } & \multicolumn{2}{|c|}{ Male students } & \multirow{2}{*}{$\begin{array}{l}\text { Differences between } \\
\text { the genders }\end{array}$} \\
\hline & Frequency & Proportion & Frequency & Proportion & Frequency & Proportion & \\
\hline Immediately & 533 & $24.3 \%$ & 375 & $24.0 \%$ & 155 & $24.6 \%$ & - \\
\hline $15 \mathrm{~min}$ & 760 & $34.6 \%$ & 494 & $31.6 \%$ & 238 & $37.7 \%$ & $\chi^{2}=7.553 ; P=0.006$ \\
\hline $30 \mathrm{~min}$ & 553 & $25.2 \%$ & 427 & $27.3 \%$ & 146 & $23.1 \%$ & $\chi^{2}=4.073 ; P=0.044$ \\
\hline $\mathrm{I} \mathrm{h}$ & 226 & $10.3 \%$ & 168 & $10.7 \%$ & 62 & $9.8 \%$ & - \\
\hline $\mathrm{I} .5 \mathrm{~h}$ & 74 & $3.4 \%$ & 59 & $3.8 \%$ & 19 & $3.0 \%$ & - \\
\hline $2 \mathrm{~h}$ & 37 & $1.7 \%$ & 33 & $2.1 \%$ & 8 & $1.3 \%$ & - \\
\hline $3 \mathrm{~h}$ & 10 & $0.5 \%$ & 7 & $0.4 \%$ & 3 & $0.5 \%$ & - \\
\hline$>3 \mathrm{~h}$ & 1 & $0.1 \%$ & 2 & 0.1 & - & - & - \\
\hline
\end{tabular}

prevalence of insomnia $\left(\chi^{2}=20.261 ; P=0.000\right)$. For details see Table 4.

\section{Multivariate model of influence factors in insomnia}

As reported in Table 5, some of the previously introduced variables were incorporated in univariate and multivariate logistic regression models to estimate odd ratios (gender, long-term student, late riser, going to bed after midnight, sleeping short, fitful sleep). Univariate logistic regression models (unadjusted estimates) show ORs between 1.55 and 6.10 with no significant results for the variables "long-term student" and "going to bed after midnight." Minimal (genderadjusted) multivariate logistic regression models show comparable results. A third multivariate logistic regression model adjusting for all incorporated variables found three stable variables still maintaining significance: (1) rising late (adjusted $\mathrm{OR}=3.60$ ), (2) sleeping short (adjusted $\mathrm{OR}=3.48$ ), and (3) fitful sleep (adjusted OR = 4.37).

\section{Subjectively reported self-efficacy}

Self-efficacy, measured by the GSE scale, was significantly higher in students without sleep problems $(\mathrm{M}=28.67$, $\mathrm{SD}=4.98$ ) compared with the sample suffering from insomnia $(\mathrm{M}=24.48, \mathrm{SD}=5.88), t=8.99, P=0.000$. The GSE score was significantly correlated with time needed to fall asleep $(r=-0.208, P<0.001)$, but not with overall sleep duration $(r=0.035)$. Whereas no significant difference concerning self-efficacy was detected between short, normal, or long sleepers, $F(2,2824)=2.70, P=0.067$ (short sleeper $\mathrm{M}=27.67 \mathrm{SD}=5.99$; normal sleeper $\mathrm{M}=28.36, \mathrm{SD}=4.99$; long sleeper $\mathrm{M}=28.40, \mathrm{SD}=5.36)$. Furthermore, male students showed a significantly higher score $(\mathrm{M}=28.88$; $\mathrm{SD}=5.25)$ in self-efficacy than females measured by the GSE scale $(\mathrm{M}=27.81, \mathrm{SD}=5.05), t=4.48, P=0.000$.

\section{Discussion}

Recent studies have shown that sleep problems are common among university students worldwide with prevalence rates of $4.7 \%$ to $73 \% .{ }^{2,3,5-10,29,30}$ The results of our study are in-line with previous findings and indicate that sleep problems are also common in German university students: in sum, $14.9 \%$ report difficulties falling asleep, requiring more than 30 minutes to fall asleep at least three times a week over a period of 1 month. However, more women report difficulty falling asleep than men $(14.1 \%$ vs $15.7 \%)$. This rate is higher than the prevalence reported by Taylor et al. ${ }^{1}$ Furthermore, just over one quarter of the sample (25.9\%) reported frequent waking at night and regarded this as disturbing. A third of students (33.3\%) reported fitful sleep at least three nights per week. At least $7.7 \%$ suffered

Table 3 Short and long sleep and associations with prevalence of insomnia

\begin{tabular}{llllll}
\hline & $\begin{array}{l}\text { Average sleep } \\
\text { duration }(\mathbf{m i n})\end{array}$ & Prevalence of insomnia & & \\
\cline { 3 - 6 } & Short sleepers ( $<$ I SD) & Normal sleepers & Long sleepers (>I SD) \\
\hline Overall sample & $M=456.00$ & $52 / 265$ & $105 / 1676$ & $13 / 255$ & $\chi^{2}=59.998 ;$ \\
(gender adjusted) & $(S D=70.84)$ & $19.6 \%$ & $6.3 \%$ & $5.1 \%$ & $P=0.000$ \\
Males & $M=450.31$ & $17 / 84$ & $21 / 434$ & $1 / 113$ & $\chi^{2}=35.439 ;$ \\
& $(S D=68.62)$ & $20.2 \%$ & $4.8 \%$ & $0.9 \%$ & $P=0.000$ \\
Females & $M=461.66$ & $32 / 170$ & $97 / 1166$ & $16 / 229$ & $\chi^{2}=21.131 ;$ \\
& $(S D=72.57)$ & $18.8 \%$ & $8.3 \%$ & $7.0 \%$ & $P=0.000$ \\
\hline
\end{tabular}

Abbreviations: $M$, mean; SD, standard deviation. 
Table 4 Time getting up and associations with prevalence of insomnia

\begin{tabular}{|c|c|c|c|c|}
\hline Classification & Get up time & Frequency & Percentage & Prevalence of insomnia \\
\hline \multirow[t]{3}{*}{ Early } & $5 \mathrm{am}$ & 17 & 0.8 & $58 / 927$ \\
\hline & $6 \mathrm{am}$ & 271 & 12.3 & $6.3 \%$ \\
\hline & $7 \mathrm{am}$ & 638 & 29.1 & \\
\hline \multirow[t]{2}{*}{ Normal } & $8 \mathrm{am}$ & 652 & 29.7 & $76 / 1026$ \\
\hline & $9 \mathrm{am}$ & 375 & 17.1 & $7.4 \%$ \\
\hline \multirow[t]{4}{*}{ Late } & $10 \mathrm{am}$ & 133 & 6.0 & $36 / 242$ \\
\hline & II am & 66 & 3.0 & $14.9 \%$ \\
\hline & $12 \mathrm{pm}$ & 30 & 1.4 & \\
\hline & After $12 \mathrm{pm}$ & 14 & 0.6 & \\
\hline
\end{tabular}

from all symptoms, such as difficulty falling asleep, frequent night waking, and daily impairments. This rate was below the prevalence of $9.4 \%$ reported by Taylor et al, ${ }^{1}$ but we have to consider that that study focused on the problem of falling asleep as an insomnia complaint. Furthermore, our results correspond with Hardison et al's study. ${ }^{31}$ One has to take into account that differences may occur due to different definition criteria; in our study, the symptoms were diagnosed on the basis of frequencies per night/week and over a period of 1 month. Other studies, however, selected answer categories such as "often," "rarely," or "yes" or "no" without numerical data., ${ }^{2}$ "Therefore, all of the sleep-related results described, such as difficulty falling asleep, night waking, and fitful sleep, are clinically relevant outcomes, as they can be declared as insomnia or insomnia symptoms, related to definition criteria. ${ }^{1-3,5-10,12,29-31}$

All sleep difficulties were more common in females than in males, which corresponds with previous findings about adults and older persons $\mathrm{s}^{32-34}$ but is in contrast with the findings of Lindberg and colleagues ${ }^{35}$ who examined younger persons. Therefore, our study provides evidence that sleep problems are more prevalent among women even in a young adult population.

Focusing on the sleep-related risk factors, we detected rising late (adjusted OR $=3.60$ ), short sleep (adjusted
$\mathrm{OR}=3.48$ ), and fitful sleep (adjusted $\mathrm{OR}=4.37$ ) as the main factors for insomnia. These sleep-related factors may especially apply to university students, as the high variability of starting times for courses allowed them to change sleep patterns easily. These results are also in-line with previous studies reporting that students are sleep deprived. ${ }^{13,16}$ Additionally, a challenging lifestyle, such as meeting friends late and having classes late in the morning, might allow young adults to establish irregular sleep-wake rhythms. As well as these changes in lifestyle, the extent of academic demands often leads to stress. ${ }^{13,14}$

The role of self-efficacy in the relationship of university academic demands and sleep was also considered in this study. Results showed a significant relationship between self-efficacy and insomnia: self-efficacy was lower in students suffering from insomnia. Moreover, self-efficacy was significantly correlated with the time needed to fall asleep but not with the sleep duration. These results are in accordance with the findings of Bouchard and colleagues. ${ }^{25}$ One could anticipate that high self-efficacy might be a protective factor for sleep problems; in contrast, low selfefficacy seems to be a risk factor for sleep problems and, thus, should be kept in mind in the prevention and therapy of sleep disorders.

Table 5 Logistic regression models evaluating the association between insomnia and previously introduced variables

\begin{tabular}{|c|c|c|c|}
\hline \multirow[t]{2}{*}{ Predictor variables } & \multirow{2}{*}{$\begin{array}{l}\text { OR }(95 \% \mathrm{Cl}) \text { for insomnia } \\
\text { Univariate logistic } \\
\text { regression models } \\
\text { (unadjusted estimates) }\end{array}$} & \multicolumn{2}{|l|}{ Adj OR $(95 \% \mathrm{Cl})$ for insomnia } \\
\hline & & $\begin{array}{l}\text { Minimal multivariate logistic } \\
\text { regression models } \\
\text { (gender-adjusted estimates) }\end{array}$ & $\begin{array}{l}\text { Multivariate logistic regression } \\
\text { model of all variables }\end{array}$ \\
\hline Gender & $1.55(1.08-2.24)^{*}$ & - & $1.37(0.92-2.04)$ \\
\hline Long-term student & $1.62(0.87-3.03)$ & $1.66(0.89-3.11)$ & $1.96(0.99-3.90)$ \\
\hline Late riser & $2.32(1.56-3.45)^{* *}$ & $2.45(1.64-3.66)^{* *}$ & $3.60(2.19-5.91)^{* *}$ \\
\hline Going to bed after midnight & $1.34(0.96-1.88)$ & $1.46(1.04-2.06)^{*}$ & $0.71(0.46-1.09)$ \\
\hline Sleeping short $(<I S D)$ & $3.20(2.24-4.57)^{* *}$ & $3.29(2.30-4.7 \mathrm{I})^{* *}$ & $3.48(2.29-5.30)^{* *}$ \\
\hline Fitful sleep (3×/week) & $6.10(4.34-8.57)^{* *}$ & $6.00(4.27-8.44)^{* *}$ & $4.37(3.03-6.28)^{* *}$ \\
\hline
\end{tabular}

Notes: *Statistically significant at $P<0.05$; **statistically significant at $P<0.01$.

Abbreviations: adj OR, adjusted odds ratio; $\mathrm{Cl}$, confidence interval; OR, odds ratio. 
Our results showed that between $14.1 \%$ and $33.3 \%$ of participants suffered from at least one insomnia symptom. Taken into account that sleep problems are discussed as a cause for learning problems, outcomes of exams might be worse for subjects with insomnia. ${ }^{16,17}$

Furthermore, sleep problems are associated with numerous complaints in social, ${ }^{16}$ psychological, and physical health ${ }^{18}$ and should be considered as an influencing factor in developing suicidal thoughts or suicide attempts. ${ }^{2}$

Although it is unknown whether insomnia symptoms lead to decreased mental health or whether mental problems lead to sleep disorders such as insomnia in university students, the results of this study reveal that sleep problems, especially insomnia, are a problem for university students to the same extent as in the general population. To our knowledge, the current study is the first one in Germany focusing on the investigation of prevalence of insomnia and the association between sleep problems and self-efficacy among university students.

Several methodological limitations of our study have to be noted. First of all, the relation of sleep parameters, sleep habits, insomnia symptoms, and self-efficacy were assessed in a cross-sectional way and without objective measurements. Thus, it is not possible to answer the question as to whether sleep symptoms, especially insomnia, are a precursor to, or a consequence of, specific lifestyle, workload, or mental health problems. In the future, more longitudinal studies as well as detailed subjective instruments, such as sleep diaries and objective data, are needed to answer these questions. Furthermore, it was not possible to evaluate all of the interesting influencing factors within one questionnaire; therefore, data concerning the level of physical activity, menstrual cycles of females, or workload were not included.

Sleep problems often have numerous negative consequences such as daily impairment and susceptibility to the onset of major psychiatric disorders. Therefore, sleep behavior and sleep problems are important and influential issues in public health. It might be helpful if university information centers considered the impact of healthy sleep on mental health, daily functioning, and work productivity. Furthermore, other studies should be provided to respond to the gap in knowledge of sleep and its difficulties among young adults at university.

\section{Disclosure}

The authors have no conflicts of interest to declare in this work.

\section{References}

1. Taylor DJ, Gardener CE, Bramoweth AD, et al. Insomnia and mental health in college students. Behav Sleep Med. 2011;9(2):107-116.

2. Nadorff MR, Nazem S, Fiske A. Insomnia symptoms, nightmares, and suicidal ideation in a college student sample. Sleep. 2011;34(1):93-98.

3. Sweileh WM, Ali IA, Sawalha AF, Abu-Taha AS, Zyoud SH, Al-Jabi SW. Sleep habits and sleep problems among Palestinian students. Child Adolesc Psychiatry Ment Health. 2011;5(1):25.

4. Regestein Q, Natarajan V, Pavlova M, Kawasaki S, Gleason R, Koff E. Sleep debt and depression in female college students. Psychiatry Res. 2010;176(1):34-39.

5. Moo-Estrella J, Perez-Benitez H, Solis-Rodriquez F, ArankowskySandoval G. Evaluation of depressive symptoms and sleep alterations in college students. Arch Med Res. 2005;36(4):393-398.

6. Marzieh N, Bandi MF, Kaffashi S. Sleep patterns in medical students and residents. Arch Iran Med. 2009;12(6):542-549.

7. Tsai LL, Li SP. Sleep patterns in college students. Gender and grade differences. J Psychosom Res. 2004;56:231-237.

8. Tsui YY, Wing YK. A study on the sleep patterns and problems of university business students in Honk Kong. J Am Coll Health. 2009;58(2):167-176.

9. Rahm L. [Subjective sleep quality and stress processing. Forum Stress and Sleep Research 1.] In: Becker-Carus C, editor. [Current Psychophysiological Sleep Research]. Münster: Lit Verlag; 1995:42-54. German.

10. BuboltzWC, BrownF, Soper B. Sleep habits and patterns of college students: a preliminary study. J Am Coll Health. 2001;50(3):131-135.

11. Ban DJ, Lee TJ. Sleep duration, subjective sleep disturbances and associated factors among university students in Korea. J Korean Med Sci. 2001;16:475-480.

12. Loayza MP, Ponte TS, Carvalho CG, et al. Associations between mental health screening by self-report questionnaire and insomnia in medical students. Arq Neuropsiquiatr. 2001;59(2):180-185.

13. Lund HG, Reider BD, Whiting AB, Prichard JR. Sleep patterns and predictors of disturbed sleep in a large population of college students. J Adolesc Health. 2010;46(2):124-132.

14. Stock C, Krämer A. [Psychosocial stress and psychosomatic complaints from students: results of a longitudinal study]. In: Sonntag U, Gräser S, Stock C, Krämer A, editors. [Health Promoting Universities]. Weinheim und München: Juventa Verlag; 2000:127-138. German.

15. Paulsen VM, Shaver JL. Stress, support, psychological states and sleep. Soc Sci Med. 1991;32(11):1237-1243.

16. Schleider K, Güntert M. [Characteristics and conditions of the student's learning and work disruptions - an inventory]. Beiträge zur Hochschulforschung. 2009;31:8-27. German.

17. Engle-Friedmann M, Riela S, Golan R, et al. The effect of sleep loss on next day effort. J Sleep Res. 2003;12(2):123-124.

18. Morin CM, Rodrigue S, Ivers H. Role of stress, arousal, and coping skills in primary insomnia. Psychosom Med. 2004;65:259-267.

19. Hoyt M, Thomas K, Epstein D, Dirkens S. Coping style and sleep quality in men with cancer. Ann Behav Med. 2009;37(1):88-93.

20. Diehl M, Hay E. Risk and resilience factors in coping with daily stress in adulthood: the role of age, self-concept incoherence, and personal control. Dev psychol. 2010;46(5):1132-1146.

21. Sadeh A, Keinan G, Daon K. Effects of stress on sleep: the moderating role of coping style. Health Psychol. 2004;23(5):542-545.

22. Klomegah RY. Predictors of academic performance of university students: an application of the goal efficacy model. Coll Stud J. 2007;41(2):407-415.

23. Bandura A. Perceived self-efficacy in cognitive development and functioning. Educ Psychol. 1993;28(2):117-148.

24. Bandura A. Self-efficacy: The Exercise of Control. New York, NY: Freeman; 1997. 
25. Bouchard S, Bastien C, Morin CM. Self-efficacy and adherence to cognitive-behavioral treatment of insomnia. Behav Sleep Med 2003;1(4):187-199.

26. Schwarzer R, Jerusalem M. Generalized self-efficacy scale. In Weinman J, Wright S, Johnston M. Measures in Health Psychology: A User's Portfolio. Causal and Control Beliefs. Windsor: NFER-NELSON; 1995:35-37.

27. American Academy of Sleep Medicine (AASM). International Classification of Sleep Disorders - Second Edition (ICSD-2). 2nd ed. Rochester, IL: AASM; 2005.

28. Lichtstein KL, Durrence HH, Taylor DJ, Bush Riedel BW. Quantitative criteria for insomnia. Behav Res Ther. 2003;41(4):427-445.

29. Preisegolaviciute E, Leskauskas D, Adomaitiene V. Associations of quality of sleep with lifestyle factors and profile of studies among Lithuanian students. Medicina (Kaunas). 2010;46(7):482-489.

30. Medeiros AL, Mendes DB, Lima PF, Araujo JF. The relationship between sleep-wake cycle and academic performance in medical students. Biol Rhythm Res. 2001;32(2):263-270.
31. Hardison HG, Neimeyer RA, Lichstein KL. Insomnia and complicated grief symptoms in bereaved college students. Behav Sleep Med. 2005;3(2): 99-111.

32. Hohagen F, Rink K, Käppler C, et al. Prevalence and treatment of insomnia in general population. A longitudinal study. Eur Arch Psych Clin neurosci. 1993;243:329-336.

33. Kling ME, Quan SF, Kaltenborn WT, Lobowitz MD. Risk factors associated with complaints of insomnia in a general adult population. Influence of previous complaints of insomnia. Arch Med. 1992;152(8): 1634-1637.

34. Reyner A, Horne JA. Gender- and age related differences in sleep determined by home-recorded sleep logs and actimetry from 400 adults. Sleep. 1995;18:127-134.

35. Lindberg E, Janson C, Gislason T, Bjornsson E, Hetta J, Boman G. Sleep disturbances in a young adult population: Can gender differences be explained by differences in psychological status? Sleep. 1997;20: $381-387$.

\section{Publish your work in this journal}

Nature and Science of Sleep is an international, peer-reviewed, open access journal covering all aspects of sleep science and sleep medicine, including the neurophysiology and functions of sleep, the genetics of sleep, sleep and society, biological rhythms, dreaming, sleep disorders and therapy, and strategies to optimize healthy sleep. The journal welcomes

\section{Dovepress}

original research, clinical \& epidemiological studies, reviews \& evaluations, case reports and extended reports. The manuscript management system is completely online and includes a very quick and fair peerreview system, which is all easy to use. Visit http://www.dovepress.com/ testimonials.php to read real quotes from published authors. 